\title{
Utilization of a Multimembrane Inlet and a Cyclic Sudden Sampling Introduction Mode in Membrane Inlet Mass Spectrometry
}

\author{
O. S. Viktorova, V. T. Kogan, and S. A. Manninen \\ Plasma Division, Nuclear and Space Physics Laboratory, A. F. Ioffe Physico-Technical Institute, St. Petersburg, \\ Russia
}

T. Kotiaho

Drug Discovery Technology Center, Department of Pharmacy, University of Helsinki, Helsinki, Finland

R. A. Ketola

VTT Processes, Post Office Box 1602, Finland

\section{B. M. Dubenskii, S. P. Parinov, and O. V. Smirnov}

ZAO Analytic, St. Petersburg, Russia

\begin{abstract}
Sudden sampling introduction into a membrane inlet mass spectrometer (MIMS) considerably improves the selectivity of the membrane inlet and is therefore applicable even for compounds with low permeabilities through a silicone membrane. In this study the basics of cyclic non-steady-state sudden increase sample injection were studied using a three-membrane inlet and a portable sector double-focusing mass spectrometer. The operational parameters of the inlet system providing the most efficient enrichment of volatile organic compounds (VOCs) in air were defined. Simulation of the diffusion process following sudden sample introduction into the three-membrane inlet was also carried out. Experimental testing of the threemembrane inlet system with the cyclic sudden sample injection mode for benzene, toluene, styrene, and xylene in air was performed. The simulation and the experimental results demonstrated that, when this mode is used, the VOCs/nitrogen relative enrichment factor of samples introduced into the mass spectrometer equipped with a three-membrane inlet is increased by a factor of $\sim 10^{5}$ compared with a direct introduction method. This effect may be used to decrease detection limits of compounds obtained with mass spectrometry to decrease matrix flow through the inlet at the same detection limits. (J Am Soc Mass Spectrom 2004, 15, 823-831) (C) 2004 American Society for Mass Spectrometry
\end{abstract}

$\mathrm{M}$ ultimembrane inlet systems have earlier been used as interfaces for gas chromatographymass spectrometry in a quasi-steady state flow introduction mode [1,2]. Very large enrichment factors for organic compounds in a hydrogen matrix were obtained with two types of membranes [1]. One of them, a silicone membrane, resulted in efficient permeation and concentration of the analytes from the hydrogen matrix into a mass spectrometer and the other, a silver-palladium separator, permitted permeation of hydrogen out of the inlet system. The necessity to

Published online April 15, 2004

Address reprint requests to Dr. V. T. Kogan, Plasma Division, Nuclear and Space Physics Laboratory, A. F. Ioffe Physico-Technical Institute, 194021 Polytechnicheskaya 26, St. Petersburg, Russia. E-mail: Victor.Kogan@mail. ioffe.ru maintain high temperature of the silver-palladium membrane and its specificity restricted the possibilities of this system. The other type of separator, a Llewellyn inlet system [2], utilizes multiple silicone membranes coupled with an orifice inlet for the enrichment of volatile organic compounds (VOCs) in different matrices during quasi-steady state flow introduction. However, experimental tasks may require: (1) Changing of sample flow into the mass spectrometer (e.g., for elimination of pump system overload with increasing VOCs concentration in a sample), (2) proportioning of enrichment effects of compounds with different permeation coefficients through the membrane (e.g., for avoidance of masking effects of compounds with similar mass spectra).

An inlet system with $\mathrm{N}$ consecutive membranes 


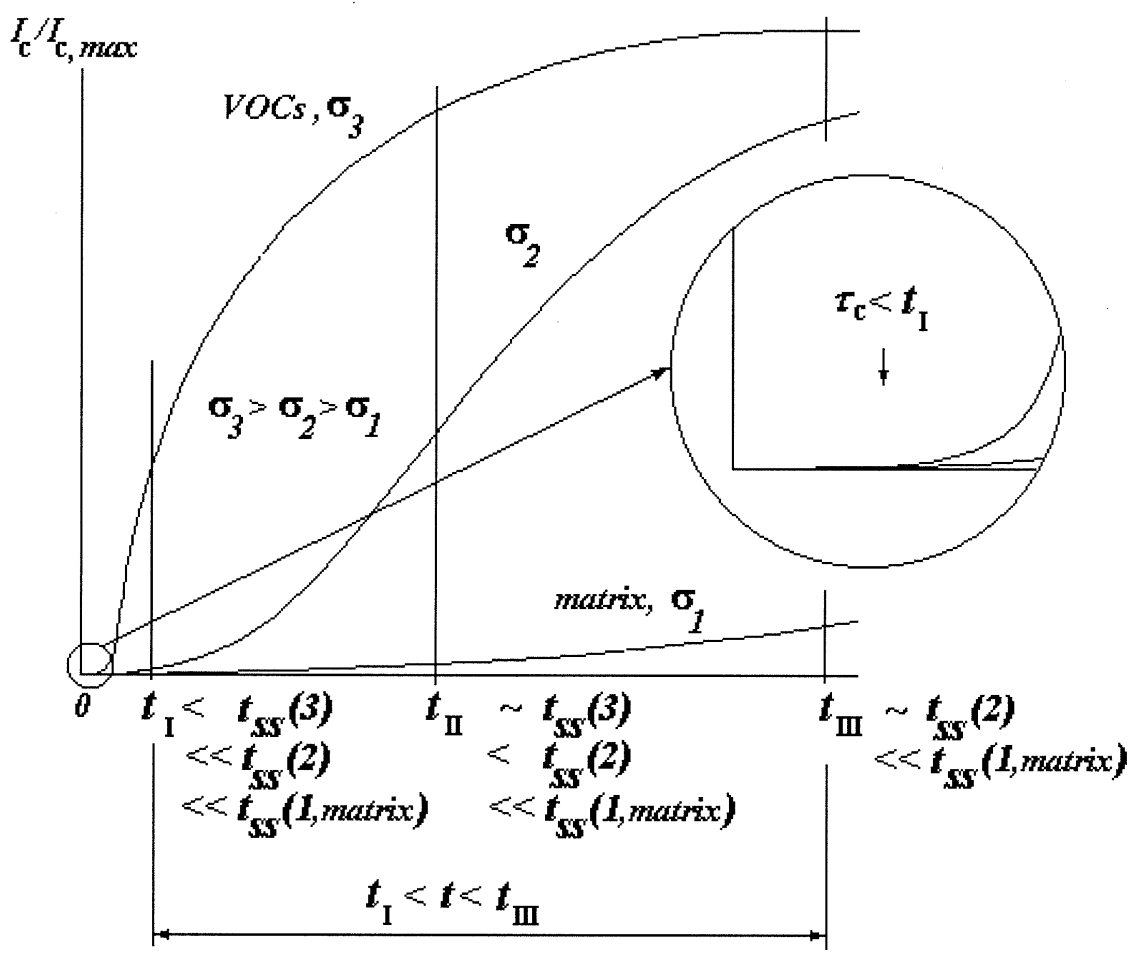

Figure 1. Fluxes of compounds $(\mathbf{c}=\mathbf{1 , 2 , 3})$ through the multimembrane inlet system into a mass spectrometer and relative enrichment of the sample with compounds with the different permeabilities $\left(\boldsymbol{\sigma}_{\mathrm{c}}\right)$ in non-steady-state sudden sampling introduction mode depend on the extension of the time interval between the moment of sample supply to the inlet system and the time of measurement $\mathbf{t}_{\mathrm{I}}, \mathbf{t}_{\mathrm{II}}$, or $\mathbf{t}_{\mathrm{III}}$, where $\mathbf{t}_{\mathbf{c s s}}$ is the time required to achieve steady state flow of Compound $\mathbf{c}$ through the entire membrane inlet, $\tau_{\mathrm{c}}$ is the response time of Compound $\mathrm{c}$ for a one membrane interface.

together with non-steady-state flow sample introduction mode for analyte enrichment in membrane inlet mass spectrometry (MIMS), was presented by Kogan and Viktorova [3]. The experimental test showed that fourteen-fold higher enrichment factors for butane in air could be achieved using a double-membrane inlet compared with a single-membrane inlet. Analytical calculations were also performed in the study, but they gave only an approximate estimation of the permeation. In order to increase the reliability of the calculations a numerical simulation method was introduced successfully to study non-steady sample diffusion processes observed in single-interfaceMIMS [4-8].

The goal of this study was to demonstrate the advantages of the cyclic non-steady-state sudden increase sample injection mode through the multimembrane inlet in the analysis of gases and VOCs in air both experimentally and by numerical simulation. This study also has to show the intercoupling between the inlet permeations and the other parameters, that allows changing the total sample flow through the inlet system as well as relation of the enrichment effects of compounds, simply by suitable choice of the measurement time interval $t_{I I}, t_{I I}, t_{I I I}$ (Figure 1).

\section{Experimental}

\section{Instrumentation}

A portable double-focusing mass spectrometer [9] with a mass range of 10-200 $\mathrm{u}$ and electron impact ionization $(80 \mathrm{eV})$ was used. The mass spectrometer was equipped with sheet membrane inlets having one, two or three membranes [3]. The material of the sheet membrane was polydimethylsiloxane (SSP-M100, Specialty Silicone Products Inc., Ballston Spa, NY) with a thickness of $100 \mu \mathrm{m}$ or $30 \mu \mathrm{m}$. Results were analyzed using a calculation program developed at A. F. Ioffe PhysicoTechnical Institute [9].

\section{Standards}

The test compounds used were: propane $99 \%$, butane $99 \%$, toluene $99 \%$, benzene $99 \%$, styrene $99 \%$, and p-xylene 99\%, all from VNIIM, St. Petersburg, Russia. Gas standards of propane and butane were prepared in two-liter bottles which were filled with air at room temperature. Gas standards of toluene, benzene, styrene, and p-xylene of $1.18 \mathrm{ppm}-2.18 \mathrm{ppm}$ (or 5.6 $\mathrm{mg} / \mathrm{m}^{3}-7.8 \mathrm{mg} / \mathrm{m}^{3}$ ) concentrations in $95 \%$ nitrogen and $5 \%$ oxygen mixture were prepared using a head 


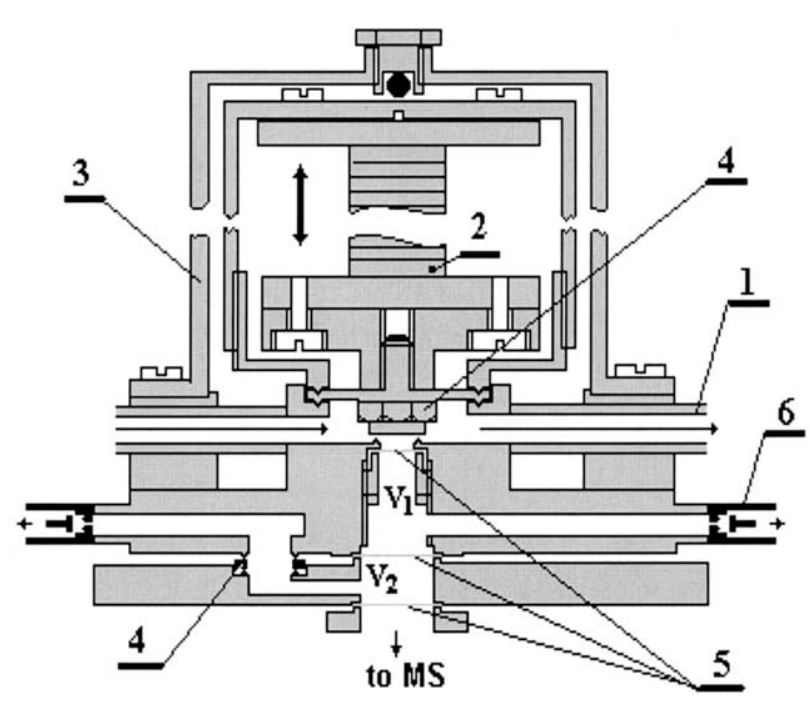

Figure 2. Schematic design of the multimembrane inlet system. (1) A tube with a flow of a sample, (2) a piezo-electric lock, (3) a body, (4) vacuum compression, (5) membranes, and (6) valves.

space vapor-gas source (HSVS) [10], allowing the preparation of gas mixtures with vapor concentrations from 0.01 to $1000 \mathrm{mg} / \mathrm{m}^{3}$ for volatile organic compounds. The uncertainty in the preparation of the gas mixtures with the HSVS is $2-7 \%$ at constant temperature.

\section{Results and Discussion}

Design of the Multimembrane Inlet

and Characteristics of the Cyclic Sudden

Sampling Introduction Mode

Multimembrane inlet design. A schematic picture of the membrane inlet is presented in Figure 2. The main components of the inlet are: (1) A tube containing a flow of the sample, (2) a piezo-electric lock, (3) a body, (4) vacuum compression, (5) silicone membranes, and (6) valves, connected to a vacuum pump. The maintenance of vacuum in the inlet system between measurement cycles is performed by pumping via the valves (6). The pumping rate through the open valves must considerably exceed the permeation rate of VOCs through the next membrane. The inlet design allows increased analyte partial pressures in the spaces between membranes as a function of their permeability after sudden sample introduction to the inlet. The greatest enrichment of VOCs compared with the matrix is observed during the non-steady-state stage of sample permeation (see below).

Operation mode of the inlet. In order to obtain an increased enrichment effect with the membrane inlet presented in Figure 2, the cyclic sudden sampling introduction mode must be used. This mode can be obtained by two different methods. First: (a) The initial state: the lock (2) is closed, two valves (6) are opened for a little; (b) when valves (6) are closed and the lock (2) is opened, enrichment process is started; (c) at $\mathbf{t}$ we obtain a spectrum of a sample; (d) return to the initial state. Second: The lock (2) is opened for all monitoring interval; (a) the initial state: valves (6) are opened for a little; (b) when valves (6) are closed enrichment process is started; (c) at $\mathbf{t}$ we obtain a spectrum of a sample; (d) return to the initial state.

Only the first of these methods was used in this work, but the second method has an advantage theoretically. As at this method the lock (2) is opened for all monitoring intervals, sample compounds are dissolved in material of the first membrane almost as much as in the case of the steady-state flow mode. It means that for all monitoring interval at the sample side of the membrane the compound concentrations have to correspond to a sample composition and the compound distribution coefficient. During each measuring cycle at the vacuum side of membrane the compound concentrations has to be changed substantially, but always its magnitudes are much lower than at the sample side (see eq 1c below). Therefore, pressure increase for the first volume in every cycle of monitoring process (except the beginning of the first cycle) will start without delay caused by forming of a steady-state flow through the membrane and will not decrease enrichment efficiency. This gain plays a vital role, particularly for a thick material. The main advantage of this way is to have a chance to apply a thick material for the first membrane as the maximum pressure differential is exerted on it.

The start of each cycle is the time point zero, i.e., $\mathrm{t}=$ 0 . The cyclic sudden sampling mode allows preconcentration of a compound, c, with permeability $\boldsymbol{\sigma}_{\mathbf{c}}$ higher than the permeability $\boldsymbol{\sigma}_{\text {mat }}$ of the carrier gas (matrix) if mass analysis is carried out at $t<t_{c \text { ss }}$, where $t_{c \text { ss }}$ is the time required to achieve steady state flow of Compound $\mathrm{c}$ through the entire membrane inlet.

The enrichment effect becomes significant in the following conditions:

(a) sample composition must be homogeneous,

(b) $\sigma_{\mathrm{c}} \gg \sigma_{\text {mat }}$ (c) $\mathrm{t} \ll \mathrm{t}_{\mathrm{c} \mathrm{ss}}$ or $\mathrm{P}_{\mathrm{c}, \mathrm{n}} \gg \mathrm{P}_{\mathrm{c}, \mathrm{n}+1}$, (d) $\tau_{\mathrm{c}} \ll \mathrm{t}$,

where $P_{c, n}$ is a partial pressure of Compound $\mathbf{c}$ in $\mathbf{V}_{\mathbf{n}}$ volume, $\mathbf{n}$ is the number of the space between the membranes and $\tau_{\mathrm{c}}$ is the response time of Compound $\mathrm{c}$ for a one membrane interface.

If the permeability of VOCs compared to that of the matrix is more than 100-fold, sample pressure inside the inlet system is defined by $\mathrm{P}_{\mathrm{n}}<\mathrm{P}_{0} / 100$ during the time it takes to reach steady-state flow of VOCs through the inlet $\left(t_{s s}\right)$, where $P_{0}$ is a sudden sample pressure increase of the matrix compound before the first membrane. Under these conditions the influence of diffusion of VOCs in spaces between the membranes is insignificant. 

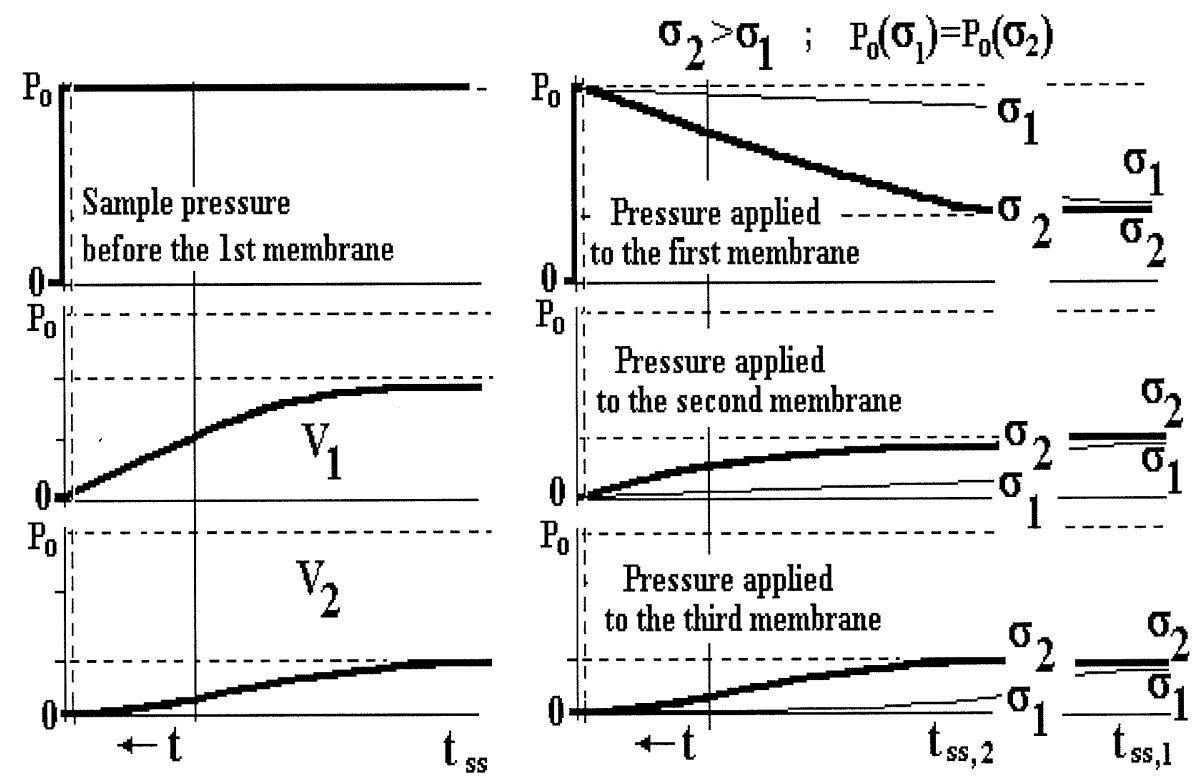

Figure 3. Partial pressures of compounds in a sample with equal initial concentration and in the spaces of three-membrane inlet system with similar interfaces on time scale $\sim t_{s s}$.

\section{Calculations}

An analytic approximation. To evaluate the performance of a multimembrane inlet under conditions defined by (eq 1), we used the simplest design with identical membranes (membrane area S, thickness $l$, material $\sigma_{\mathrm{c}}$ ), and spaces $(\mathrm{V})$.

Taking into account the first Fick's law the Compound $\mathrm{c}$ flow into volume $\mathrm{V}_{\mathbf{n}}$ may be written as:

$$
\mathrm{I}_{\mathrm{c}}=\mathrm{J}_{\mathrm{c}} \text { (flow rate) } \mathrm{S}=\sigma_{\mathrm{c}}\left(\mathrm{P}_{\mathrm{c}, \mathrm{n}-1}-\mathrm{P}_{\mathrm{c}, \mathrm{n}}\right) /(l) \mathrm{S},
$$

and for the Compound $\mathrm{c}$ flow out of volume $\mathrm{V}_{\mathbf{n}}$ :

$$
\mathrm{I}_{\mathrm{c}}=\mathrm{J}_{\mathrm{c}}(\text { flow rate }) \mathrm{S}=\sigma_{\mathrm{c}}\left(\mathrm{P}_{\mathrm{c}, \mathrm{n}}-\mathrm{P}_{\mathrm{c}, \mathrm{n}+1}\right) /(l) \mathrm{S} \text {. }
$$

Then the change of partial pressure $\mathrm{P}_{\mathbf{c}, \mathbf{n}}$ of Compound $\mathbf{c}$ in cell $\mathbf{n}$ involving two neighbor membranes and intermediate volume $V_{\mathbf{n}}$ after sample delivery to the membrane inlet and up to the moment $t$, on conditions that eq 1 is ensured, can be described by equation set for $\boldsymbol{n}$-th volume:

$$
\begin{aligned}
& \partial \mathrm{P}_{\mathrm{c}, \mathrm{n}} / \partial \mathrm{t}= \sigma_{\mathrm{c}} S\left(\mathrm{P}_{\mathrm{c}, \mathrm{n}-1}-\mathrm{P}_{\mathrm{c}, \mathrm{n}}\right) /(l \mathrm{~V})-\sigma_{\mathrm{c}} S\left(\mathrm{P}_{\mathrm{c}, \mathrm{n}}\right. \\
&\left.-\mathrm{P}_{\mathrm{c}, \mathrm{n}+1}\right) /(l \mathrm{~V}) \cong \mathrm{P}_{\mathrm{c}, \mathrm{n}-1} \sigma_{\mathrm{c}} S /(l \mathrm{~V}) . \\
& \mathrm{P}_{\mathrm{c}, \mathrm{n}}=\sigma_{\mathrm{c}} \mathrm{S} /(\mathrm{V} l) \int \mathrm{P}_{\mathrm{c}, \mathrm{n}-1} \mathrm{dt}+\mathrm{C} .
\end{aligned}
$$

The partial pressure of Component $\mathbf{c}$ in each volume $n$ may be expressed through the initial partial pressure $\mathrm{P}_{\mathbf{c}, 0}$. In the first volume:

$$
\begin{aligned}
\mathrm{P}_{\mathrm{c}, 1} & =\sigma_{\mathrm{c}} \mathrm{S} /(\mathrm{V} l) \int \mathrm{P}_{\mathrm{c}, 0} \mathrm{dt}=\mathrm{P}_{\mathrm{c}, 0} \sigma_{\mathrm{c}} \mathrm{S} /(\mathrm{V} l) \mathrm{t}, \mathrm{C}(\mathrm{t} \\
& =0)=0 .
\end{aligned}
$$

In order to fulfill the condition (eq 1c) for $P_{c, 1}$ and $P_{c, 0}$ the system parameters should meet the condition: $\mathrm{P}_{\mathbf{c}, 1} \ll$ $\mathrm{P}_{\mathbf{c}, 0}$ or $\mathrm{P}_{\mathbf{c}, 1} \ll \mathrm{P}_{\mathbf{c}, 1} /\left[\sigma_{\mathbf{c}} \mathrm{S} /(\mathrm{Vl}) \mathrm{t}\right]$ from eq 5 , or $1 \ll 1 /\left[\sigma_{\mathbf{c}}\right.$ $\mathrm{S} /(\mathrm{Vl}) \mathrm{t}]$ or:

$$
\mathrm{t} \ll(\mathrm{Vl}) /\left(\sigma_{\mathrm{C}} \mathrm{S}\right)
$$

To fulfill the condition (eq 1c) for the next volumes the system parameters should meet the same (eq 7) condition. It means that steady-state flow through the inlet system at time $t$ is not achieved and generalized partial pressure $P_{c, \mathbf{n}}$ can be expressed by:

$$
\mathrm{P}_{\mathrm{c}, \mathrm{n}}=\mathrm{P}_{\mathrm{c}, 0}\left(\sigma_{\mathrm{c}} \mathrm{S} /(\mathrm{V} l)\right)^{\mathrm{n}} \mathrm{t}^{\mathrm{n}} / \mathrm{n} !
$$

The flow density $\mathrm{J}_{\mathrm{c}}$ of Component $\mathrm{c}$ after the inlet is proportional to its partial pressure in front of the last membrane, which gives the total enrichment effect of the N-membrane inlet system:

$$
E \cong\left(\sigma_{\mathrm{c}} / \sigma_{\mathrm{mat}}\right)^{\mathrm{N}}
$$

A steady-state introduction mode with this design does not give any advantage compared to a singlemembrane inlet (Figure 3). But for non-steady-state sudden sampling introduction mode it follows (eq 8) that the flow of Compound $\mathbf{c}$ at the inlet's vent is increased as a function of $\mathrm{t}^{\mathrm{N}-1}$ and the time scale of the increase depends on $\sigma_{\mathrm{c}}$. This allows to obtain efficient enrichment $(\mathrm{E})$ of the c-component by increasing the number of membranes (Figure 4).

Membrane diffusion process. Gas diffusion in the nonsteady-state flow through the sheet membrane of area S, with thickness $l \ll S^{1 / 2}$, may be considered as a one- 


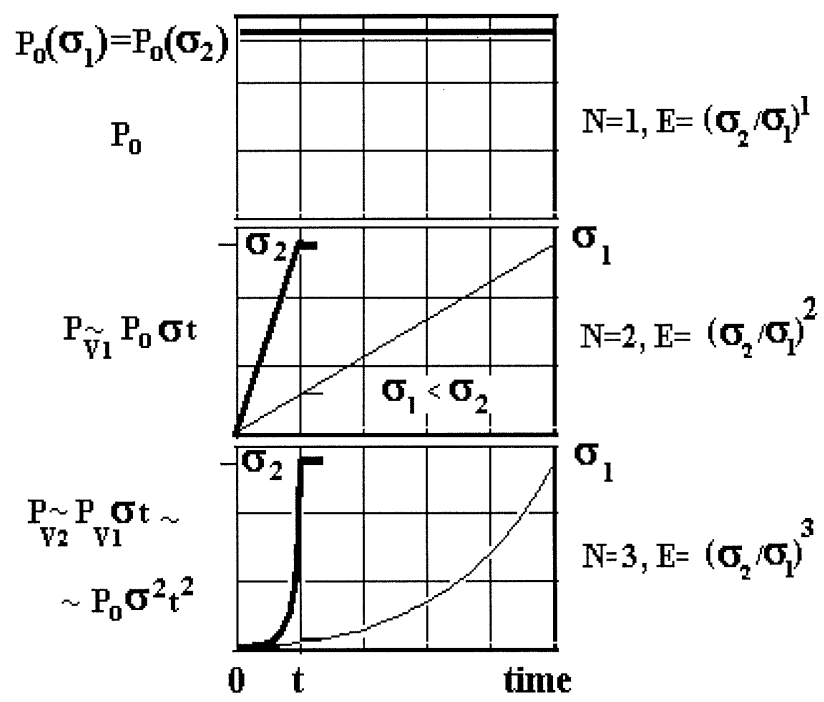

Figure 4. Partial pressures of compounds in a sample with equal initial concentration and in the spaces of three-membrane inlet system with similar interfaces on time scale $\sim t \ll t_{\text {ss }}$.

dimensional process. The gas particle flow density through the sheet membrane is expressed according to Fick's first law by the ratio:

$$
J(x, t)=-D \frac{\partial c(x, t)}{\partial x}
$$

where $\mathrm{D}$ is a diffusion coefficient of the membrane $\left(\mathrm{cm}^{2} / \mathrm{s}\right), \mathrm{c}(\mathrm{x}, \mathrm{t})$ is a gas concentration $(\mathrm{mol} / \mathrm{L})$. Fick's second law is represented by the ratio:

$$
\frac{\partial c(x, t)}{\partial t}=-\frac{\partial J(x, t)}{\partial x}
$$

This completely describes the diffusion process of the compounds in the membrane.

At the border of the membrane the gas concentration experienced a step change:

$$
\mathrm{c}_{\text {in }}=\mu \mathrm{c}_{\mathrm{out}}
$$

the value of which is defined by the membrane distribution ratio $(\mu)$.

A numerical simulation. To describe the diffusion process through the inlet system, which consists of several membranes separated by spaces between the membranes, we must divide every membrane into $n$ layers of thickness $h$ (Figure 5). The gas concentration inside each layer is considered to be similar. Thus, instead of continuous distribution, concentration of each component on a coordinate can be presented by a set of discrete elements of matrix values $\mathbf{c}_{i, j}$, consisting of $3 n$ terms, where the first index is the number of the membrane and the second is the number of the layer. The time interval of the non-steady-state diffusion process, following the sudden increase of the sample pressure before the first membrane, is divided into several time step-intervals $\Delta \mathrm{t}$. If at step $k$ the concentration in the layers is known, the flow density between the steps can be calculated from the equation:

$$
J_{i, j}{ }^{(k)}=D \frac{c_{i, j}{ }^{(k)}-c_{i, j+1}{ }^{(k)}}{h}, i=1 \ldots 3, j=1 \ldots n-1,
$$

which is the end-differential analog of eq 10 . Here $\mathrm{J}_{i, j}{ }^{(k)}$ is the flow density at step $k$ from layer $j$ to layer $j+1$. The concentration in the internal membrane layers at the next time step-interval is calculated from equation:

$$
c_{i, j}{ }^{(k+1)}=c_{i, j}{ }^{(k)}+\Delta t \frac{J_{i, j-1}{ }^{(k)}-J_{i, j}{ }^{(k)}}{h}, i=1 \ldots 3, j=2 \ldots n-1,
$$

which is the end-differential analog of eq 11. According to the condition (eq 12), the concentration in the external membrane layer is determined by the ratios:

$$
\begin{aligned}
& \mathrm{C}_{1,1}{ }^{(k)}=\mu \cdot \mathrm{C}_{0}, \\
& \mathrm{C}_{1, n}{ }^{(k)}=\mathrm{C}_{2,1}{ }^{(k)}=\mu \cdot \mathrm{C}_{1}{ }^{(k)}, \\
& \mathrm{C}_{2, n}{ }^{(k)}=\mathrm{c}_{3,1}{ }^{(k)}=\mu \cdot \mathrm{C}_{2}{ }^{(k)}, \\
& \mathrm{C}_{3, n}{ }^{(k)}=\mu \cdot \mathrm{C}_{3} .
\end{aligned}
$$

where $\mathrm{C}_{0}$ is the gas concentration in the original sample, $\mathrm{C}_{3}=0$ is the gas concentration in the ion source of the mass spectrometer, $\mathrm{C}_{1}{ }^{(k)}$ and $\mathrm{C}_{2}{ }^{(k)}$ are gas concentrations in the spaces between the membranes at time $\mathrm{t}=k \cdot \Delta \mathrm{t}$. $\mathrm{C}_{0}$ and $\mathrm{C}_{3}$ are constants, which are determined from the boundary conditions. $\mathrm{C}_{1}{ }^{(k)}$ and $\mathrm{C}_{2}{ }^{(k)}$ are calculated for every time step-interval. For this purpose the capacity of the space $\left(\mathrm{V}_{i}^{\prime}\right)$ considered is defined by the capacity of space between the membranes $\left(\mathrm{V}_{i}\right)$ and the capacity of the bordering membrane layers. Flow $\mathrm{J}_{i, n-1}$ enters this space and $\mathrm{J}_{i+1,1}$ exits this space. Therefore, $\mathrm{C}_{i}{ }^{(k+1)}$ is

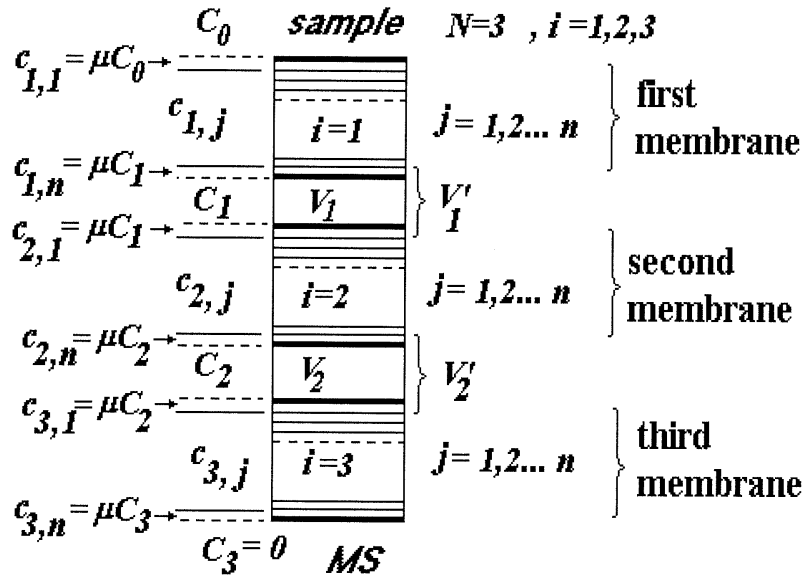

Figure 5. Numerical model of the three-membrane inlet system. 
Table 1. The enrichment factors of gas compounds compared to nitrogen in different membrane inlet systems

\begin{tabular}{|c|c|c|c|c|c|c|c|c|}
\hline \multicolumn{9}{|c|}{ Enrichment effect, $E_{c}$} \\
\hline \multicolumn{3}{|c|}{ Membrane-compound features } & \multicolumn{3}{|c|}{ Double-membrane inlet, $\left\{\mathrm{t}_{\mathrm{SS}} / \mathrm{t}\right\},[\mathrm{t} / \tau]$} & \multicolumn{3}{|c|}{ Three-membrane inlet, $\left\{\mathrm{t}_{\mathrm{ss}} / \mathrm{t}\right\},[\mathrm{t} / \tau]$} \\
\hline $\begin{array}{l}\text { Compound } \\
\text { c }\end{array}$ & $\begin{array}{c}\tau_{100} \mu \mathrm{m}, \\
\mathrm{S}\end{array}$ & $\begin{array}{c}\mathrm{E}^{11} \text { c,cal. }= \\
\left(\sigma_{\mathrm{c}} / \boldsymbol{\sigma}_{\text {mat }}\right) \\
\left\{\mathrm{t}_{\mathrm{SS}} / \mathrm{t}\right\}=\infty, \\
{[\mathrm{t} / \tau]=\infty}\end{array}$ & $\begin{array}{l}\mathrm{E}^{11} \text { c,cal, mAx } \\
=\left(\sigma_{\mathbf{c}} / \sigma_{\text {mat }}\right)^{2}\end{array}$ & $\begin{array}{c}\mathrm{E}^{11}{ }^{{ }^{\prime}} l l= \\
30 \mu \mathrm{m}\end{array}$ & $\begin{array}{l}E^{11}{ }_{c}^{\prime} l= \\
100 \mu \mathrm{m}\end{array}$ & $\begin{array}{c}E^{111} \text { c,cal, MAX } \\
\left(\sigma_{\mathbf{c}} / \sigma_{\text {mat }}\right)^{3}\end{array}$ & $\begin{array}{c}\mathrm{E}^{111}{ }_{\mathrm{c}}^{\prime} l= \\
\mathbf{3 0} \boldsymbol{\mu \mathrm { m }}\end{array}$ & $\begin{array}{c}\mathrm{E}^{111}{ }_{\mathrm{c}}^{\prime} l= \\
100 \mu \mathrm{m}\end{array}$ \\
\hline $\mathrm{N}_{2}$ & 5 & 1 & 1 & 1 & 1 & 1 & 1 & 1 \\
\hline $\mathrm{O}_{2}$ & 4 & 1.9 & $3.6 \approx(1.9)^{2}$ & & $\begin{array}{c}3.6 \\
\{\sim 100\},[\sim 12]\end{array}$ & $7 \approx(1.9)^{3}$ & $\begin{array}{c}7 \\
\{\sim 80\}_{,}[\sim 80]\end{array}$ & $\begin{array}{c}7 \\
\{\sim 150\},[\sim 12]\end{array}$ \\
\hline Ar & 5 & 2.4 & & & & $14 \approx(2.4)^{3}$ & $\begin{array}{c}14 \\
\{\sim 60\},[\sim 80]\end{array}$ & $\begin{array}{c}14 \\
\{\sim 120\},[\sim 12]\end{array}$ \\
\hline $\mathrm{CO}_{2}$ & 8 & 9.1 & & & & $750 \approx(9.1)^{3}$ & $\begin{array}{c}650 \\
\{\sim 15\}_{,}[\sim 40]\end{array}$ & $\begin{array}{c}700 \\
\{\sim 30\},[\sim 7]\end{array}$ \\
\hline Propane & 9 & 22 & & & & $10000 \approx(22)^{3}$ & $\begin{array}{c}6000 \\
\{\sim 8\},[\sim 35]\end{array}$ & \\
\hline Butane & 11 & 40 & $1600 \approx(40)^{2}$ & $\begin{array}{c}750 \\
\{\sim 7\},[\sim 30]\end{array}$ & $\begin{array}{c}560 \\
\{\sim 5\},[\sim 6]\end{array}$ & $64000=(40)^{3}$ & $\begin{array}{c}16300 \\
\{\sim 5\},[\sim 30]\end{array}$ & \\
\hline
\end{tabular}

(Bold type-calculated values, regular type-experimental values)

determined from the following equation:

$$
C_{i}^{(k+1)}=C_{i}^{(k)}+\Delta t \cdot S \frac{J_{i, n-1}{ }^{(k)}-J_{i+1,1}{ }^{(k)}}{V_{i}^{\prime}}
$$

where $\mathrm{V}_{i}{ }^{\prime}=\mathrm{V}_{i}+2 \cdot \mathrm{S} \cdot \mathrm{h} \cdot \mu-$ is the capacity of the space $(i$ $=1,2)$.

Calculations were carried out according to eqs (1316) with initial conditions $c_{1,1}^{(0)}=\mu \cdot C_{0}$ and $c_{i, j}^{(0)}=0\left(c_{1,1}^{(0)} \notin\right.$ $\left.\mathrm{c}_{i, j}^{(0)}\right)$. The flow density behind the inlet system at any point of time is defined from the equation:

$$
\mathrm{J}_{\text {exit }}(k \Delta \mathrm{t})=\mathrm{J}_{3, n-1}{ }^{(k)} .
$$

\section{Results and Discussion}

The larger number of membranes in the inlet makes it necessary to increase (a) the area of membranes, so that a sufficient sample flow can be supplied into the mass spectrometer, (b) spaces between the membranes so that the typical time to reach steady-state flow through the multimembrane inlet is longer than the response time with one membrane and (c) the sample flow in the sampling tube (eq 1a) so that a homogenous sample is constantly provided for the membrane inlet.

Thanks to extension of the membrane area, the multimembrane inlets increase the sample quantity entering the membrane inlet system. Due to the short measurement cycles, the greatest part of the sample (all matrix compounds with low permeability) does not reach the mass spectrometer. This part of the sample is necessary to pump out of the spaces between the membranes, which require an additional vacuum pump in the instrumental set-up.

The thickness of a membrane, $l$, is chosen, on the one hand, to meet the requirements of the construction's mechanical strength and, on the other hand, to obtain high sensitivity in the analysis of VOCs. Correlation of the membrane areas $\mathrm{S}$ and the intermediate spaces $\mathrm{V}$ must [3] satisfy the conditions (eq 7).

The permeability of the test compounds compared with that of nitrogen $\left(\sigma_{\mathrm{c}} / \sigma_{\text {mat }}\right)$ through a silicone membrane were determined with a portable mass spectrometer [9]. The enrichment factors measured for gases using the multimembrane inlet systems are presented in Table 1. The maximum calculated enrichment effect was obtained using the ratios $\left(\sigma_{\mathrm{c}} / \sigma_{\text {mat }}\right)$ from the analytical estimation.

The response time value $\left(\tau_{\mathrm{c}}\right)$ of Compound $\mathbf{c}$ for $\mathbf{a}$ one membrane interface at its sudden pressure increase is usually determined by the time it takes for the flow to increase $\left(t_{c, 10 \%-90 \%}\right)$ from $10 \%$ to $90 \%$ of its maximum value [11]:

$$
\tau_{\mathrm{c}}=\mathrm{t}_{\mathrm{c}, 10 \%-90 \%}
$$

The measured $\tau_{\mathrm{c}}$ values for a $100 \mu \mathrm{m}$ thick silicone membrane are presented in the second column of Table 1. To estimate the $\tau_{c}$ values for a similar membrane material with another thickness, we can use the parameters of the $100 \mu \mathrm{m}$ thick membrane [11]:

$$
\tau_{\mathrm{c}}=2.342 l^{2} /\left(\pi^{2} \mathrm{D}_{\mathrm{c}}\right)
$$

Experiments were performed using membrane inlets with different numbers of membranes and varying membrane thicknesses $\left(l, \tau_{\mathrm{c}}\right)$, (eq 19), inlet constructions $\left(\mathrm{Vl} / \mathrm{S}, \mathrm{t}_{\mathrm{c}, \mathrm{ss}}\right),(\mathrm{eq} 7)$, and durations of measurement cycles $(t)$. The test mixture contained propane and butane in air. The differences in membrane parameters, inlet constructions and cycle durations were expressed through $\left\{t_{c, s s} / t\right\}$ and $\left[t / \tau_{c}\right]$ relations, where $t_{c \text { ss }}$ is the time required to achieve steady state flow of Compound $\mathbf{c}$ through the entire membrane inlet, and $\tau_{\mathbf{c}}$ is a 
Table 2. The enrichment factors of VOCs in nitrogen with the three-membrane inlet system compared to the maximum calculated enrichment factor

\begin{tabular}{|c|c|c|c|}
\hline \multicolumn{4}{|c|}{$\begin{array}{c}\mathrm{E}_{\mathrm{c}}\left(\left\{\mathrm{t}_{\mathrm{c} \mathrm{ss}} / \mathrm{t}\right\} \sim 1,\left[\mathrm{t} / \tau_{\mathrm{c}}\right] \sim 10\right) \\
\left(\sigma_{\mathrm{c}} / \sigma_{\text {mat }}\right)^{3}\end{array}$} \\
\hline Benzene & Toluene & Styrene & P-xylene \\
\hline $\begin{array}{c}(0.63 \pm 0,06) * 10^{5} \\
\sim \mathbf{1 0}^{\mathbf{6}}\end{array}$ & $\begin{array}{c}(0.75 \pm 0,06) * 10^{5} \\
\sim \mathbf{1 0}^{\mathbf{6}}\end{array}$ & $\begin{array}{c}(0.43 \pm \\
\pm 0,04) * 10^{5} \\
\sim 1 \mathbf{1 0}^{\mathbf{6}}\end{array}$ & $\begin{array}{c}(0.58 \pm 0,06) * 10^{5} \\
\sim \mathbf{1 0}^{\mathbf{6}}\end{array}$ \\
\hline
\end{tabular}

(Bold type-calculated values, regular type-experimental values)

response time value of Compound $\mathrm{c}$ through a one membrane interface. Data in Table 1 and Table 2 show the dependence of the actual relative enrichment effect provided by the multimembrane inlet systems on these relations. The sample flow rate was set to $20 \mathrm{ml} / \mathrm{min}$ per square millimeter of a $30 \mu \mathrm{m}$ membrane in order to approach the maximum enrichment effect.

Addition of every membrane should be accompanied by the increase of all membrane area in the inlet system in order to decrease the limits of detection of VOCs. In this case to get minimal limits of detection the membrane area (or area to thickness ratio) is multiplied by $\sim \mathrm{N}\left(\sigma_{\mathrm{c}} / \sigma_{\mathrm{m}}\right)$. Increase of VOCs flux as well as dropping of matrix flow into the mass spectrometer are the major factors for portable mass spectrometers designed for long-term monitoring measurements.

Membrane inlet systems of the portable mass spectrometer with ion pump for gases and VOCs analysis were designed with the help of the results obtained during test gas mixture [9]. The design parameters of one-membrane system were $0.1 \mathrm{~mm}$ thickness, $\mathrm{S}^{1}=0.1$ $\mathrm{mm}^{2}$. Multimembrane inlets were equipped with mechanical or piezo-electric lock. There parameters were: Two-membrane system includes $0.1 \mathrm{~mm}$ membrane thickness, $S_{1}^{11}=S_{2}^{11}=1 \mathrm{~mm}^{2}, V_{1}^{11}=30 \mathrm{~mm}^{3}$; threemembrane inlet includes $0.03 \mathrm{~mm}$ membrane thickness, $\mathrm{S}_{1}^{111}=15 \mathrm{~mm}^{2}, \mathrm{~S}_{2}^{111}=\mathrm{S}_{3}^{111}=30 \mathrm{~mm}^{2}, \mathrm{~V}_{1}^{111}=800 \mathrm{~mm}^{3}$, $\mathrm{V}_{2}^{111}=600 \mathrm{~mm}^{3}$.

For organic compounds with high permeability the preliminary information concerning qualitative matrix and sample composition is very significant for selection of the optimal operating parameters of a membrane inlet mass spectrometer. Enrichment of both sample and background compounds (organic or inorganic) with high permeability increases as the number of membranes $(\mathrm{N})$ in the inlet system increases. The mass spectra of air constituents introduced into the portable mass spectrometer through orifice and one membrane inlets in permanent mode and through two- and threemembrane inlets with non-steady-state sudden sam-
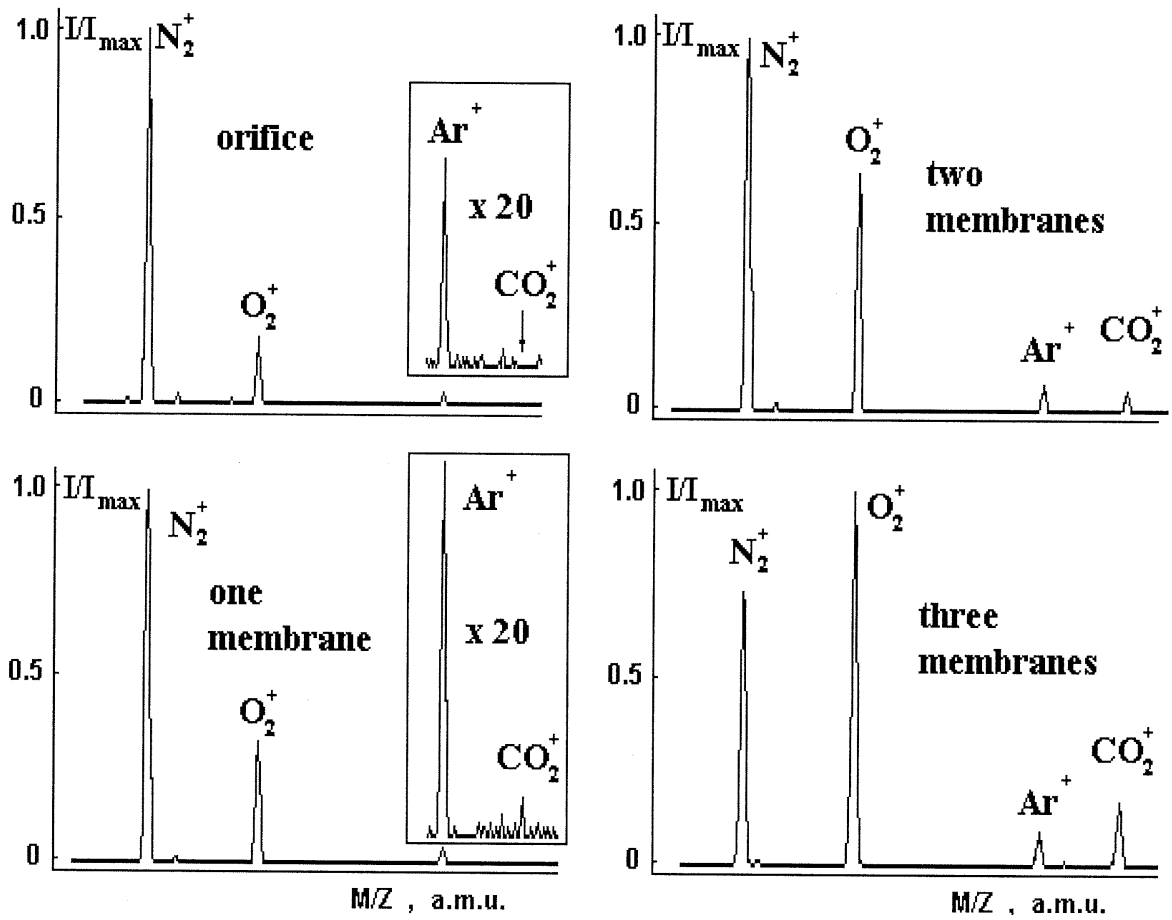

Figure 6. EI $(80 \mathrm{eV})$ mass spectra of an air sample measured with orifice, one-membrane, two-membrane and three-membrane inlet systems (composition of the air sample: $\mathrm{N}_{2}-78 \%, \mathrm{O}_{2}-21 \%$, Ar $\left.1 \%, \mathrm{CO}_{2}-0.04 \%\right)$. 


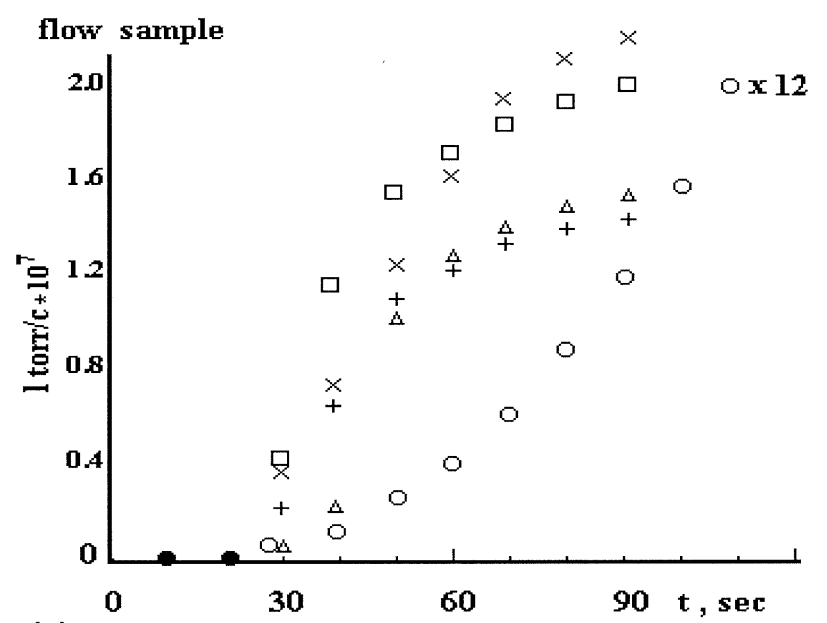

(a)

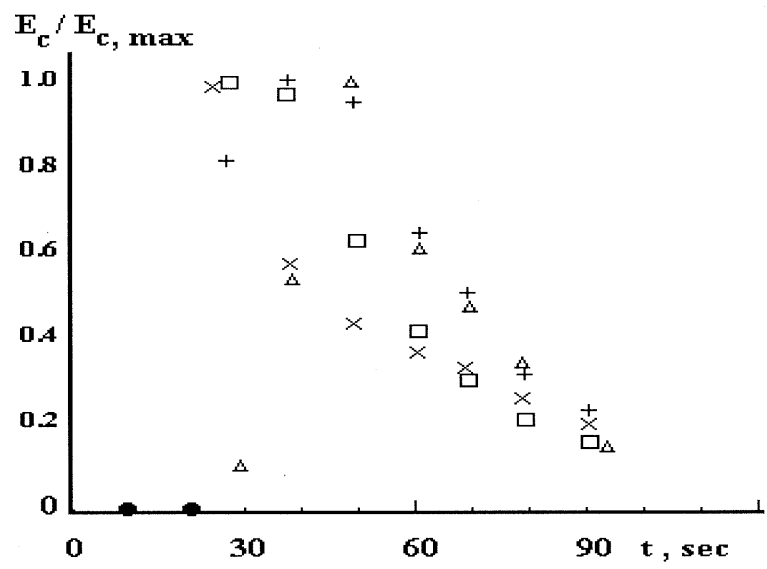

(b)

Figure 7. (a) Flow intensity of benzene (x), toluene (open saquare), styrene (open triangle), p-xylene $(+)$, oxygen (open circle), and coincident points (filled circle) through three-membrane inlet system took into account the response of mass spectrometer for a mixture of benzene $\mathrm{m} / \mathrm{z}=78(2.18 \mathrm{ppm})$, toluene $\mathrm{m} / \mathrm{z}=92(1.76$ $\mathrm{ppm}$ ), styrene (open triangle) $\mathrm{m} / \mathrm{z}=104(1.18 \mathrm{ppm})$, and p-xylene $(+) \mathrm{m} / z=106(1.18 \mathrm{ppm})$ in $95 \%$ nitrogen $+5 \%$ oxygen, and the relation of the peak area of the monitored ion of compound to the sum of all peak areas in its EI mass spectrum, instrument transmission, and electron-impact ionization effectiveness of compounds. (b) Time dependence of relative enrichment factors for VOCs.

pling injection with $\mathrm{t}=60 \mathrm{~s}$ are presented in Figure 6 . They demonstrate that the number of membranes considerably change matrix composition passing through the inlet.

The response for a VOC mixture containing 2.18 ppm $\left(7.8 \mathrm{mg} / \mathrm{m}^{3}\right)$ benzene, $1.76 \mathrm{ppm}\left(7.5 \mathrm{mg} / \mathrm{m}^{3}\right)$ toluene, $1.18 \mathrm{ppm}\left(5.6 \mathrm{mg} / \mathrm{m}^{3}\right)$ styrene and $1.18 \mathrm{ppm}$ $\left(5.6 \mathrm{mg} / \mathrm{m}^{3}\right) \mathrm{p}$-xylene in synthetic air $(95 \%$ nitrogen and $5 \%$ oxygen) recorded using the same instrumental set-up is shown in Figure 7a. Figure $7 \mathrm{~b}$ shows the time dependence of relative enrichment factors for VOCs. Time interval, which gives the best experimental enrichment factor, $E_{\mathrm{c}^{\prime}}$ for all compounds simultaneously, is about $60 \mathrm{~s}$.
Experimental and calculated enrichment factors of the gases (Table 1) and VOCs (Table 2) compared with nitrogen were determined using the relation:

$$
\begin{aligned}
E_{\mathrm{c}}(t)= & \mathrm{C}_{\mathrm{O} 2} / \mathrm{C}_{\mathrm{c}} * \mathrm{~A}_{\mathrm{c}} / \mathrm{A}_{\mathrm{O} 2} * \mathrm{~A}_{\mathrm{O} 2} / \mathrm{A}_{\mathrm{N} 2} * \mathrm{~T}_{\mathrm{O} 2} / \mathrm{T}_{\mathrm{j}} \\
& * \mathrm{~K}_{\mathrm{mat}} / \mathrm{K}_{\mathrm{c}} * \mathrm{~B}_{\mathrm{O} 2} / \mathrm{B}_{\mathrm{c}^{\prime}}
\end{aligned}
$$

where $C_{c}$ is the volume concentration of Compound $\mathrm{c}$ in the initial sample, $A_{c}$ is the peak area registered by the detector, $\mathrm{T}_{\mathbf{c}}$ is the transmission of the mass analyzer for analyte ions (e.g., for benzene $m / z 78$ and for toluene $m / z$ 92) compared with oxygen $(m / z 32), K_{c}$ is a coefficient of relative ionization by electron impact $\left(\mathrm{K}_{\text {mat }} \approx \mathrm{K}_{\mathrm{O} 2} \approx\right.$ $\mathrm{K}_{\mathrm{N} 2} \approx 1$ ), and $\mathrm{B}_{\mathrm{c}}$ is the relation of the peak area of the monitored ion of Compound $\mathrm{c}$ to the sum of all peak areas in its EI mass spectrum, where $\mathrm{T}_{\mathbf{c}}, \mathrm{K}_{\mathrm{c}}$, and $\mathrm{B}_{\mathrm{c}}$ are given through direct sample introduction.

The high relative enrichment at the exit of multimembrane systems can be used to decrease limits of detection of VOCs as to decrease total sample flow into mass-spectrometer. A portable mass spectrometer of low sensitivity was used in this work. The limits of detection of benzene in air with the instrument equipped with one-membrane inlet is $10 \mathrm{ppm}$, with two-membrane inlet is $2 \mathrm{ppm}$, and with three-membrane inlet is $30 \mathrm{ppb}$. At the same time air flux into the mass spectrometer was reduced relative to one-membrane inlet system: 20 times for two-membrane system and 30 times for three-membrane system.

A numerical simulation was performed for propane, butane, and benzene in air. Permeability and diffusion coefficients of these compounds through SSP-M100 silicone membrane were determined previously [9]. As an example, the simulation and experimental results for benzene and oxygen are presented in Figure 8. It can be observed that the experimental response of both compounds has a delay with respect to the numerical simulation response curves. The authors suppose that the time lag is due to the adsorption of analytes at low pressure ( $\ll 1$ torr) onto the internal stainless steel surfaces of the inlet system.

A similar effect was reported by Lauritsen and coworkers [12, 13]. During the experiments it was observed that the time lag is approximately the same for all the analytes and that it is reproducible. When the numerical simulation results are shifted on the time axis by $22 \pm 2 \mathrm{~s}$, the agreement between the experimental results and the simulation results is very good.

Enrichment of the gaseous compounds and VOCs with the non-steady-state sudden sampling introduction method into a mass spectrometer via a multimembrane inlet system was found to be more effective when a thin silicone membrane was used. It is evident from the results for butane and propane presented in Table 1.

The analytical approximation method can be used to estimate enrichment factors of inlet design with rather high accuracy for compounds with a relative permeability compared with those of nitrogen less than ten (Table 1 , from oxygen to carbon dioxide). For compounds with 


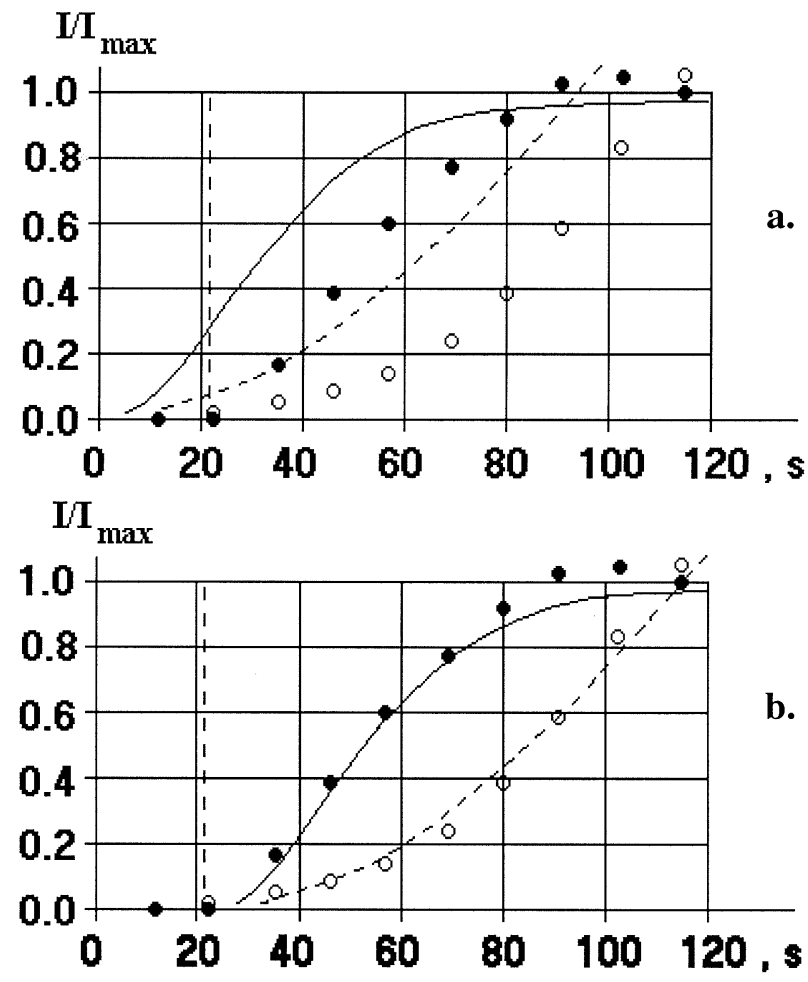

Figure 8. Simulated (emdash, endash) and experimental (filled circle, open circle) responses of benzene (filled circle, emdash) and oxygen (open circle, endash) with the three-membrane inlet system from a sample containing $3 \mathrm{ppm}$ benzene in $95 \%$ nitrogen + $5 \%$ oxygen. (a) Simulated and experimental results, $\mathbf{I}$ (benzene) is normalized to $\mathbf{I}_{\max }$ (benzene) and $\mathbf{I}$ (oxygen) is normalized to $20^{*} I_{\max }$ (benzene); (b) fitting of results: $22 \mathrm{~s}$ shifting of simulated curves.

higher permeability values the analytical approximation doesn't give enough precision and therefore, the numerical simulation method presented in this study must be used. The numerical simulation method takes into account diffusion and absorption processes of each analyte in the separate membranes and the sample pressure increase in the spaces between the membranes. Adsorption of the compounds onto the internal surfaces of the inlets (excluding membrane material) is not taken into account in the numerical simulation, but the only effect of the adsorption was the time lag observed in the responses of the analytes.

The enrichment effects obtained for the compounds used in the study were very high: Enrichment factors up to $10^{5}$ compared with nitrogen were measured for VOCs in air with the cyclic non-steady-state sudden sampling introduction mode in a mass spectrometer equipped with the three-membrane inlet.

\section{Conclusions}

The membrane inlet system with three membranes in series effectively enriches VOCs from air when the cyclic non-steady-state sudden sampling introduction mode is used. The experimental results and the numerical simulation results both showed that the multimem- brane inlet systems may increase the sensitivity of a mass spectrometer in VOC analysis by several orders of magnitude. The enrichment of organic compounds in a sample strongly depends on the time period of each cycle of sampling introduction, size of the membrane, and the volume of the spaces between the membranes. The calculations and experiments performed served to demonstrate that a larger enrichment effect can be achieved, using the same design of the membrane interface, by increasing the sample flow through the inlet. This can be obtained by decreasing the membrane thickness and the time of measurement. Another advantage of the multimembrane inlet is that it can be used for reduction the high-vacuum pump load, which is especially important for small, portable mass spectrometers with ion pumps.

\section{References}

1. Lucero, D. P.; Haley, F. C. Sample Enrichment Techniques for a Gas Chromatograph/Mass Spectrometer Analysis System. J. Gas Chromatogr. 1968, 6, 477-482.

2. Black, D. R.; Flath, R. A.; Teranishi, R. Membrane Molecular Separators for Gas Chromatographic-Mass Spectrometric Interfaces. J. Chromatogr. Sci. 1969, 7, 284-289.

3. Kogan, V. T.; Viktorova, O. S. Organic Impurity Preconcentration by a Multimembrane Inlet System of a Mass Spectrometer. Tech. Phys. Lett. 2001, 27(12), 984-986.

4. Tsai, G. J.; Austin, G. D.; Syu, M. J.; Tsao, G. T.; Hayward, M. J.; Kotiaho, T.; Cooks, R. G. Theoretical Analysis of Probe Dynamics in Flow Injection/Membrane Introduction Mass Spectrometry. Anal. Chem. 1991, 63, 2460-2465.

5. Overney, F. L.; Enke, C. G. A Mathematical Study of Sample Modulation at a Membrane Inlet Mass Spectrometer-Potential Application in Analysis of Mixtures. J. Am. Soc. Mass Spectrom. 1996, 7, 93-100.

6. Lennemann, F. Membrane Inlet Mass Spectrometry for Bioreactors. Modeling and Application for Gases and Liquids; Ph.D. Thesis, Hamburg-Harburg Technical University, Hamburg, 1999.

7. Sysoev, A. A.; Ketola, R. A.; Mattila, I.; Tarkiainen, V.; Kotiaho, T. Application of the Numerical Model Describing Analyte Permeation Through Hollow Fiber Membranes into Vacuum for Determination of Permeation Parameters of Organic Compounds in a Silicone Membrane. Int. J. Mass Spectrom. 2001, 212, 205-217.

8. Sysoev, A. A. A Mathematical Model for Kinetic Study of Analyte Permeation from Both Liquid and Gas Phases Through Hollow Fiber Membranes into Vacuum. Anal. Chem. 2000, 72, 4221-4229.

9. Kogan, V. T.; Viktorova, O. S.; Gladkov, G. J.; Chichagov, Y. V.; Tubol'tsev, Y. V. Membrane Injector for Portable Mass Spectrometer. Instrum. Experim. Techniques 2001, 44(1), 107-110.

10. Vitenberg, A. G.; Kostkina, M. I.; Ioffe, B.V. Preparation of Standard Vapor-Gas Mixtures for Gas Chromatography: Continuous Gas Extraction. Anal. Chem. 1984, 56, 2496-2500.

11. Kotiaho, T.; Lauritsen, F. R.; Choudhury, T. K.; Cooks, R. G.; Tsao, G. T. Membrane Introduction Mass Spectrometry. Anal. Chem. 1991, 63, 875A-883A.

12. Lauritsen, F. R. A New Membrane Inlet for On-Line Monitoring of Dissolved, Volatile Organic Compounds with Mass Spectrometry. Int. J. Mass Spectrom. Ion Processes 1990, 95, $168-259$.

13. Hansen, K. F.; Gylling, S.; Lauritsen, F. R. Time- and Concentration-Dependent Relative Peak Intensities Observed in Electron Impact Membrane Inlet Mass Spectra. Int. J. Mass Spectrom. Ion Processes 1996, 152, 143-155. 